\title{
Comportamento estratégico da empresa e a visão baseada em recursos: um estudo no setor varejista de material de construção
}

\author{
Strategic behavior and Resource-based View: \\ a study in construction material retail sector
}

\author{
Ronaldo Ribeiro' \\ Carlos Ricardo Rossetto ${ }^{2}$ \\ Miguel Angel Verdinelli ${ }^{3}$
}

\begin{abstract}
Resumo: Esta pesquisa tem o objetivo de analisar o relacionamento dos recursos da organização quanto ao seu comportamento estratégico na percepção dos gestores das lojas de material de construção. Para tanto, aborda a teoria de recursos, a partir da RBV (Resource-based View), e a tipologia de Miles e Snow (1978), na determinação do comportamento estratégico das organizações. Com a finalidade de atingir o objetivo proposto utilizou-se uma abordagem qualiquantitativa. A pesquisa qualitativa foi exploratória, utilizando focus group e a quantitativa descritiva, a partir de uma survey. Os resultados, quanto ao comportamento estratégico, indicam que 34,3\% das empresas são defensoras, $27,1 \%$ são reativas, $20,0 \%$ são analistas e $18,6 \%$ prospectoras. Com relação às hipóteses propostas, inexistência de diferenças nas capacidades segundo os comportamentos estratégicos, nenhuma mostrou significância estatística. Com Respeito à associação mensurada entre o comportamento estratégico e as capacidades, os prospectores são os que possuem a maior correlação positiva, verificada com as capacidades de administração. Já os reativos são os que apresentam a maior correlação negativa, também com as capacidades de administração. Conclui-se que há ausência de ajuste entre comportamentos estratégicos e os recursos e capacidades, o que pode, segundo a RBV, deixar de gerar vantagem competitiva sustentável.
\end{abstract}

Palavras-chave: Comportamento estratégico. Resource-based View (RBV). Capacidades. Lojas de material de construção.

\begin{abstract}
This study aims to investigate the relationship between the organization resources and the strategic behavior from construction material stores viewpoint. The RBV (Resource-Based View) and the Miles and Snow Typology (1978) are used in this study for determining the organization's strategic behavior. A quali-quantitave approach was used. The qualitative study was exploratory making use of the focus group technique and the quantitative descriptive analysis through a survey. The results indicated that, according to the strategic behavior, $34.3 \%$ of the organizations are defenders, $27.1 \%$ are reactors, $20 \%$ are analyzers, and $18.6 \%$ are prospectors. With regard to proposed hypothesis, there was no statistically significant capability difference according to the Studying the correlation between strategic behavior and capabilities, one can see that the prospectors are the ones that exhibit the strongest positive correlation according to the management capabilities. On the other hand, the reactors exhibit the strongest negative correlation also according to the management capabilities. One can therefore conclude that there is lack of adjustment between the strategic behavior and the resources and capabilities, which, according to the Resource-Based View, may prevent sustainable competitive advantages.
\end{abstract}

Keywords: Strategic behavior. Resource-based View (RBV). Capabilities. Construction material stores.

\section{Introdução}

A administração estratégica representa um campo acadêmico em que seus temas de interesse competem com diferentes campos vigorosos, como economia, sociologia, marketing e finanças e seus membros são oriundos de várias tradições, como economia, comportamento organizacional e marketing (NAG;

\footnotetext{
${ }^{1}$ Administração, Universidade do Vale do Itajaí - UNIVALI, SENAC Joinville - SC, Rua Ilhota, 159, Floresta, CEP 89211-595, Joinville-SC, E-mail: ronaldo@sc.senac.br

${ }^{2}$ Programa de Pós-graduação em Administração - PPGA, Universidade do Vale do Itajaí - UNIVALI, Engenharia de Produção pela Universidade Federal de Santa Catarina - UFSC, Grupo de Pesquisas em Estratégia e Redes - REDESTRAT, Rua Zanzibar do Nascimento Lins, 5, casa 22, Trindade, CEP 88.036-225, Florianópolis - SC, E-mail: rossetto@ univali.br

${ }^{3}$ Programa de Pós-graduação em Administração - PPGA, Universidade do Vale do Itajaí - UNIVALI, Oceanografia pela Universidade de São Paulo - USP, Rua Uruguai, 458, Centro, CEP 88302-202, Itajaí - SC, E-mail: nupad@univali.br
}

Recebido em 19/11/2010 — Aceito em 16/2/2011

Suporte financeiro: Nenhum. 
HAMBRICK; CHEN, 2007). Portanto, não há surpresa em perceber que existe uma variedade de definições do que seja a administração estratégica.

A dissonância também está presente no processo de formulação das estratégias. Se não há consenso na formulação da estratégia, a sua elaboração é um processo particular de cada organização, fruto da adaptação de modelos existentes (MINTZBERG, 1973) e pode ser o processo deliberado ou emergente de Mintzberg (1987), o processo formal de Ansoff, o incrementalismo lógico de Quinn (BAILEY; JOHNSON, 1995) ou as estratégias genéricas de Porter (1996).

Na década de 1990, uma nova corrente começou a ganhar corpo, a visão baseada em recursos (Resourcebased View - RBV) e as estratégias, que antes eram estabelecidas partindo-se das condições ambientais, passaram a ser formuladas a partir de seus recursos (BARNEY, 1991). Isto não significa que qualquer recurso que a empresa possui seja uma fonte de vantagem competitiva, considerada por Barney e Hesterly (2007), como a capacidade da empresa em gerar valor econômico maior do que os concorrentes. Para ter sucesso, as estratégias da organização devem ser formuladas a partir de recursos considerados raros e valiosos, que sejam insubstituíveis e de difícil imitação (BARNEY, 1991).

Portanto, mais do que possuir recursos estratégicos, a empresa deve ter clareza de que comportamento estratégico adotar para usufruir de todos os benefícios que eles podem gerar. Aliar recursos e comportamento estratégico torna-se importante para a construção de vantagem competitiva, pois cada comportamento pressupõe características diferentes que exigem recursos também distintos para que sua implementação gere os resultados desejados. Neste sentido, Miles e Snow (1978) argumentam que a empresa é fruto de um propósito articulado e de um mecanismo estabelecido para realizá-lo.

Para a maioria das empresas o ajuste às mudanças ambientais é um processo complexo e cercado de inúmeras decisões. Dentre elas, destaca-se a definição do comportamento estratégico alinhado aos seus recursos, pois, segundo Menon et al. (1999), uma estratégia sem os recursos necessários não poderá ser implementada.

A realização de estudos recentes sobre o comportamento estratégico (GULINI, 2005; ANDRETTI, 2008; MALONE et al., 2008; PLESHKO; NICKERSON, 2008; ANDREWS et al., 2009; CANCELLIER; BLAGESKI JUNIOR, 2009; TEIXEIRA; ROSSETTO; CARVALHO, 2009), assim como as pesquisas que utilizam a RBV para estudar o ajuste dos recursos ao comportamento estratégico (DI BENEDETTO; SONG, 2003; ARAGÓN-SÁNCHEZ; SÁNCHEZ-MARÍN, 2005; DESARBO et al., 2005; 2006; SONG; DI BENEDETTO; NASON, 2007), demonstram a importância de se compreender o impacto dos recursos frente ao comportamento estratégico adotado pela organização, para que se gere vantagem competitiva, diante das ameaças e oportunidades do ambiente.

$\mathrm{O}$ crescimento nos últimos anos do número de tais estudos - que relacionam os recursos ao comportamento estratégico - pode ser um indicativo de que ainda não há consenso sobre o comportamento estratégico em relação aos recursos que a organização possui e demonstram que existe um campo a ser pesquisado e melhor compreendido. É justamente neste contexto e pela escassez de estudos dessa natureza no Brasil, que esta pesquisa torna-se relevante, procurando dar sua contribuição ao campo.

Visto que as pesquisas ainda têm que demonstrar empiricamente os efeitos do ajuste dos recursos com o tipo estratégico (HUGHES; MORGAN, 2008), i.e., que as organizações focarão em diferentes tipos de recursos e capacidades dependendo de seu tipo estratégico (DESARBO et al., 2006), e partindo do pressuposto de que para a RBV as organizações deveriam alocar seus escassos recursos para desenvolver capacidades que gerem vantagem competitiva (SONG; DI BENEDETTO; NASON, 2007), o objetivo deste trabalho é analisar o relacionamento dos recursos da organização ao seu comportamento estratégico na percepção dos gestores das lojas de material de construção de Joinville-SC.

\section{Fundamentação teórica}

Para discorrer sobre a fundamentação teórica, o capítulo foi dividido por tema, iniciando-se com a RBV. Em seguida, aborda-se o comportamento estratégico e, então, o relacionamento entre os dois. Por fim, o capítulo apresenta as hipóteses que foram testadas a partir da amostra pesquisada.

\subsection{Visão baseada em recursos}

O estudo de Penrose (1959) é considerado o marco inicial sobre a teoria baseada em recursos. Para a autora, o limite ao crescimento da empresa não está no mercado, mas nos recursos que possui e, sobretudo, na maneira como são utilizados. É a partir da distinção entre os recursos e a forma como são utilizados que está a origem da singularidade das empresas (PENROSE, 1959).

A partir daquele trabalho seminal, Wernerfelt (1984) instituiu o termo Visão Baseada em Recursos, para tratar da construção de vantagem competitiva a partir dos recursos da empresa. Para esse autor, um aumento na lucratividade das empresas pode ser mais bem explicado por seus recursos do que por sua posição de mercado. Esta ideia impulsionou outros estudos (DIERICKX; COOL, 1989; BARNEY, 1991; PETERAF, 1993) a persistirem na tentativa de explicar a razão pela qual as empresas têm performances diferentes em uma mesma indústria, já que não há 
clareza do impacto do ambiente no desempenho delas (BARNEY, 1991).

Se, para Porter (1996), as empresas são homogêneas, já que no seu modelo das Forças Competitivas os recursos são facilmente transferíveis, na $\mathrm{RBV}$, a essência do sucesso está na heterogeneidade, pois os recursos são distribuídos de forma não uniforme na indústria, não sendo transferidos com tanta facilidade (BANDEIRA-DE-MELO; CUNHA, 2001).

Os recursos, para a RBV, são entendidos como os ativos, capacidades, processos organizacionais, conhecimento, informação e atributos controlados pela empresa (BARNEY, 1991). Para que sejam considerados fonte de vantagem competitiva, Barney (1991) estabelece quatro atributos que os recursos devem possuir: devem ser valiosos; raros; imperfeitamente imitáveis; e de difícil substituição.

Dierickx e Cool (1989) destacam que os recursos essenciais para a vantagem competitiva não são, necessariamente, comprados em mercados imperfeitos de fatores de produção (BARNEY, 1986), mas podem ser acumulados ao longo do tempo pela empresa, com base nas suas escolhas. Tais recursos "são idiossincráticos, não transferíveis e não imitáveis, pois não são negociáveis entre empresas" (BANDEIRADE-MELO; CUNHA, 2001).

Mais recentemente a noção de recurso tem sido ampliada, admitindo-se que seu valor é dependente, pelo menos em parte, de condições ambientais (FOSS; FOSS, 2005). Neste sentido, Crubellate, Pascucci e Grave (2008) atribuem essa evolução conceitual dos recursos na RBV à crescente importância de aspectos vinculados à legitimidade da organização, ou seja, um recurso terá valor para a organização se ela tiver reconhecimento pelo seu ajustamento ao ambiente. Assim, a legitimidade pode ser vista de duas maneiras: como um recurso, que pode ser acumulado pela organização ou como a aceitabilidade e reconhecimento que a organização conquista ao assumir pressupostos aceitos pelo ambiente (CRUBELLATE; PASCUCCI; GRAVE, 2008).

Num mercado de grandes incertezas e competição global, possuir recursos pode não ser suficiente para garantir a sustentabilidade de uma vantagem competitiva. A flexibilidade e a inovação, aliadas à capacidade dos gestores de coordenar e redefinir as competências organizacionais são marcas de empresas vencedoras (TEECE; PISANO; SHUEN, 1997). Esta habilidade para alcançar novas formas de vantagem competitiva é chamada por Teece, Pisano e Shuen (1997) de capacidade dinâmica. Por dinâmica, os autores referem-se à capacidade de renovar competências para manter a coerência como as mudanças do ambiente. Já por capacidade, os autores enfatizam o papel da administração estratégica em adaptar, integrar e reconfigurar de maneira apropriada as habilidades organizacionais, recursos e competências funcionais para se acomodar aos requisitos do ambiente em constante mudança.

De fato, se o controle de capacidades e recursos escassos é fonte de vantagem competitiva, dar atenção a questões como aquisição de habilidades, gestão do conhecimento e aprendizagem torna-se fundamental (TEECE; PISANO; SHUEN, 1997). Neste sentido, o conceito de capacidades dinâmicas é visto como sendo a habilidade da empresa em integrar, construir e reconfigurar competências internas e externas para dar atenção às rápidas mudanças ambientais. As capacidades dinâmicas refletem a habilidade da empresa em construir formas novas e inovadoras de vantagem competitiva, considerando a dependência de trajetória e as posições de mercado (LEONARDBARTON, 1992).

A criação de vantagem competitiva depende, entretanto, não somente dos recursos e capacidades da empresa, mas também do ajuste ao seu comportamento estratégico, que será abordado a seguir, a partir da tipologia de Miles e Snow (1978).

\subsection{Comportamento estratégico}

Outro interesse fundamental em estratégia é explorar as diferentes estratégias das indústrias ou mesmo entender como empresas de uma indústria têm comportamento estratégico diferente (PENG; TAN; TONG, 2004). Hambrick (2003) salienta que dos vários sistemas de classificação, a tipologia de Miles e Snow (1978) tem sido a mais duradoura, verificada e usada. Além disso, continua o autor, tem sido submetida a numerosos testes de sua validade, e, ainda mais, não só testada, mas colocada em prática (HAMBRICK, 2003).

Miles et al. (1978) afirmam que a empresa é um propósito articulado e um mecanismo estabelecido para realizá-lo. A maioria das empresas procura rever constantemente seus propósitos, adequando-os a novas realidades para interagir da melhor maneira com o ambiente. Entretanto, para muitas empresas, o processo dinâmico de ajuste ao ambiente é complexo e envolve a tomada de decisão em vários níveis da empresa (MILES et al., 1978). Para superar esta complexidade, aqueles autores propõem o estabelecimento de padrões de comportamento das organizações para descrever o processo organizacional de adaptação.

O modelo de Miles e Snow (1978) apresenta quatro tipos estratégicos: defensor, prospector, analista e reativo. Cada um dos três primeiros tipos tem sua própria configuração de tecnologia, processo e estrutura consistente com sua estratégia de mercado (MILES et al. 1978). Já o tipo reativo é, para Miles e Snow (1978), uma forma de fracasso estratégico em que existe inconsistência entre sua estratégia, tecnologia, estrutura e processo. 
A estratégia defensora é mais apropriada para organizações que se encontram em ambientes estáveis do que para as que operam em ambientes turbulentos, sendo seu maior risco a ineficiência, pois ela pode ser incapaz de responder às principais mudanças de seu ambiente. Uma organização nesta condição é pouco capaz de localizar e explorar novas áreas de oportunidade (MILES et al., 1978).

Diferentemente do defensor, a capacidade principal do prospector está em encontrar e explorar novos produtos e oportunidades de mercado. Para um prospector, manter a reputação de inovador pode ser tão importante quanto ter alta lucratividade (MILES et al., 1978). Por isso, o sucesso dos prospectores é atribuído ao desenvolvimento de novos produtos e a entrada em novos mercados (OLSON; SLATER; HULT, 2005) e à inovação tecnológica (DESARBO et al., 2005). Os prospectores reagem rapidamente às mudanças percebidas no mercado, por meio do desenvolvimento constante de novos produtos e serviços e procuram obter vantagem por meio da velocidade para produzir e comercializar diferenciação (MALONE et al., 2008).

Segundo Miles e Snow (1978), uma organização analista é aquela que tenta minimizar o risco enquanto procura maximizar suas oportunidades de lucro, ou seja, o tipo analista procura combinar as forças dos prospectores e defensores. Dito de outra forma, o analista tenta manter uma posição segura e estável no mercado, enquanto, ao mesmo tempo, movimenta-se rapidamente para acompanhar novos desenvolvimentos na indústria (PLESHKO; NICKERSON, 2008; MALONE et al., 2008).

Um quarto tipo de organização existente é o reativo, que exibe padrões inconsistentes e instáveis de ajuste ao ambiente, como assinalado anteriormente. É visto como um tipo organizacional disfuncional, por não ter uma estratégia clara (MALONE et al., 2008). O ciclo adaptativo do reativo geralmente consiste em responder inadequadamente às mudanças ambientais, apresentar desempenho insuficiente e ser relutante para agir agressivamente no futuro (MILES et al., 1978). Segundo Miles e Snow (1978), a estratégia do reativo é residual e surge quando uma das outras três estratégias é inadequadamente desempenhada.

\subsection{Tipos estratégicos e recursos}

O fato de uma empresa possuir recursos e capacidades por si só não garante uma melhoria no seu desempenho (WERNERFELT, 1984; BARNEY, 1991, SONG; DI BENEDETTO; NASON, 2007). Será a posse de recursos raros e valiosos (BARNEY, 1991) que conduzirão a empresa para vantagem competitiva sustentável e melhorarão o desempenho a longo prazo (SONG; DI BENEDETTO; NASON, 2007), ou seja, as capacidades e recursos em si mesmos não têm o efeito mais importante sobre a performance. São as interações entre os tipos estratégicos e os recursos e capacidades que geram resultados positivos sobre o desempenho (SONG; DI BENEDETTO; NASON, 2007). Neste sentido, as empresas deveriam alocar seus recursos para construir as capacidades que são mais consistentes com o seu tipo estratégico (DI BENEDETTO; SONG, 2003).

Desta forma, a aprendizagem e a distribuição da informação podem ser consideradas vitais para a consecução da vantagem competitiva. Barney (2001) afirma que a capacidade de implementação da estratégia é, em si mesma, um recurso estratégico. Uma estratégia de sucesso é resultado do ajuste entre o conhecimento necessário da estratégia e a estratégia em si (HUGHES; MORGAN, 2008). Uma estratégia pode ser escolhida de forma inadequada devido à ausência de conhecimento suficiente, o que poderá gerar um desempenho abaixo do esperado (HUGHES; MORGAN, 2008).

Os resultados de vários estudos (DI BENEDETTO; SONG, 2003; MORGAN; STRONG; MCGUINNES, 2003; DESARBO et al. ,2005; 2006; SONG; DI BENEDETTO; NASON, 2007) demonstram que não há consenso no relacionamento de recursos aos tipos estratégicos, o que mantém o interesse em pesquisas que descrevam como os recursos relacionam-se a cada tipo estratégico. Desarbo et al. (2006) sugerem, ao concluir sua pesquisa, que trabalhos futuros poderiam examinar tipos estratégicos específicos encontrados em outros contextos ambientais. Seguindo tal sugestão, este trabalho testou as hipóteses estudadas por Desarbo et al. $(2005,2006)$ nas lojas de material de construção de Joinville-SC.

\subsection{Hipóteses}

As hipóteses submetidas à prova foram elaboradas a partir das pesquisas realizadas por Desarbo et al. (2005) ao estudar 709 Unidades Estratégicas de Negócios na China, Japão e Estados Unidos e por Desarbo et al. (2006) ao estudar 216 empresas dos Estados Unidos. A partir da revisão da literatura de administração e marketing, aqueles autores agruparam as medidas a serem pesquisadas em cinco tipos de capacidades, as que foram testadas e validadas: capacidades de orientação ao mercado; capacidades tecnológicas; capacidades de marketing; capacidades de tecnologia da informação; e capacidades de administração. Do mesmo modo, neste estudo, os recursos são concebidos a partir de tais capacidades.

\subsubsection{Capacidades tecnológicas}

As capacidades tecnológicas são relacionadas à eficiência do processo de produção, redução de custos, maior consistência na entrega e maior 
competitividade (DESARBO et al., 2005), além do desenvolvimento de novos produtos e da previsão de mudanças tecnológicas na indústria (SONG; DI BENEDETTO; NASON, 2007). São habilidades internas da organização, entretanto são ditadas pelo mercado, pela concorrência, mudanças ambientais ou novas oportunidades (SONG; DI BENEDETTO; NASON, 2007).

Importante para todos os tipos estratégicos, as capacidades tecnológicas o são, especialmente, para os prospectores, visto que operam em ambientes em constante mudança (SONG; DI BENEDETTO; NASON, 2007) e utilizam a estratégia de ser o primeiro no mercado (HUGHES; MORGAN, 2008). São, portanto, portadores de múltiplas tecnologias que garantam o desenvolvimento contínuo e a ampliação de mercados e produtos (MILES et al., 1978). Por outro lado, Miles e Snow (1978) afirmam que a eficiência tecnológica é fundamental para os defensores, que buscam manter baixos custos por meio de domínios criados para absorver as saídas em bases contínuas e previsíveis. Os analistas, segundo os autores, necessitam de tecnologia que seja tanto para operar com flexibilidade como com estabilidade, caracterizando esse comportamento estratégico assemelhando-se às vezes aos prospectores, outras aos defensores.

Assim, considerando que os prospectores necessitam de inovação permanente em um ambiente de constantes mudanças, os defensores primam pela eficiência de custo e dos processos, e que os analistas precisam de tecnologia que permita o equilíbrio entre flexibilidade e estabilidade, formula-se a seguinte hipótese:

- H1: as capacidades tecnológicas não variam em relação ao comportamento estratégico das organizações.

\subsubsection{Capacidades de tecnologia da informação}

As capacidades de tecnologia da informação referem-se às capacidades que auxiliam uma organização a criar conhecimento técnico e de mercado e facilitam o fluxo da comunicação interna e a integração entre os departamentos (DESARBO et al., 2005; SONG; DI BENEDETTO; NASON, 2007).

Considerados como os que possuem as estratégias mais agressivas (PLESHKO; NICKERSON, 2008), é provável que os prospectores deem maior ênfase à inovação, tanto de produto quanto de mercado (ARAGÓN-SÁNCHEZ; SÁNCHEZ-MARÍN, 2005; OLSON; SLATER; HULT, 2005). Para isso, os prospectores necessitam de capacidade de tecnologia da informação para explorar as vantagens de serem o primeiro no mercado (DESARBO et al., 2006; HUGHES; MORGAN, 2008). Por outro lado, os defensores focam mais na eficiência de seus processos do que na inovação, o que também exige capacidade de tecnologia da informação (MILES et al., 1978).

Os analistas, por sua vez, preocupam-se com a comunicação interna, pois sua estrutura combina áreas funcionais e equipes de projetos (MILES et al., 1978). Eles precisam criar novos produtos e mercados e manter a eficiência dos mercados sob seu domínio. Portanto, também possuem a necessidade de capacidade de tecnologia da informação para manter a eficiência do processo e ao mesmo tempo possuir flexibilidade. Assim, a segunda hipótese será:

- H2: as capacidades de tecnologia da informação não variam em relação ao comportamento estratégico das organizações.

\subsubsection{Capacidades de orientação ao mercado}

Por capacidade de orientação ao mercado, Desarbo et al. (2005) entendem a capacidade da organização em criar relacionamentos duráveis com fornecedores, reter consumidores e unir-se a membros do canal de distribuição, como atacadistas e varejistas.

Apesar de poder ser argumentado que todas as organizações necessitam de um alto grau de orientação ao mercado, Song, Di Benedetto e Nason (2007) opinam que, comparado com os prospectores, os defensores precisam de um nível mais alto de capacidade de orientação ao mercado por necessitarem rapidamente se antecipar às mudanças nos mercados e às necessidades de seus clientes no intuito de manter o domínio do mercado e/ou produto. Além disso, para sustentar um nicho seguro, os defensores tendem a proteger seu domínio ao oferecer qualidade, serviços adicionais e preço, entre outros (SONG; DI BENEDETTO; NASON, 2007).

Embora os prospectores procurem sustentar sua vantagem competitiva por meio de novos produtos, mercados e tecnologia, igualmente necessitam de capacidades de orientação ao mercado. Por sua vez, os analistas, que possuem características dos prospectores e defensores, pois criam novos produtos e mercados, porém somente depois de terem sua viabilidade demonstrada, também exigem determinadas capacidades de orientação ao mercado. Considerando o exposto, que a capacidade de orientação ao mercado é importante para todos os comportamentos estratégicos, formula-se a seguinte hipótese:

- H3: as capacidades de orientação ao mercado não variam entre os comportamentos estratégicos das organizações.

\subsubsection{Capacidades de marketing}

As capacidades de marketing que incluem o conhecimento dos consumidores e dos concorrentes, 
qualidade dos serviços, habilidade em segmentar mercados, habilidade em oferecer serviços diferenciados e a eficácia da publicidade e da formação de preço (CONANT; MOKWA; VARADARAJAN, 1990) são de grande importância para os defensores manterem vantagem competitiva sustentável (DI BENEDETTO; SONG, 2003), pois estão preocupados em proteger seus consumidores e produtos atuais (MCDANIEL; KOLARI, 1987).

Os prospectores também requerem competências no planejamento e alocação de recursos de marketing e no controle de atividades de marketing (CONANT; MOKWA; VARADARAJAN, 1990), o que sugere que as capacidades de marketing são, igualmente, importantes para eles. Miles et al. (1978) argumentam que os analistas também requerem determinadas capacidades de marketing, por eles desenvolverem novos mercados e produtos e procurarem manter o domínio em mercados que já atuam. Desta forma, considerando-se a importância das capacidades de marketing para cada um dos comportamentos estratégicos, pode-se formular a seguinte hipótese:

- H4: as capacidades de marketing não variam entre os comportamentos estratégicos das organizações.

\subsubsection{Capacidades de administração}

A quinta capacidade focada na gestão da organização inclui a habilidade para integrar sistemas logísticos, controle de custos, administração financeira e de recursos humanos, previsão de vendas e administração do plano de marketing (DESARBO et al., 2005). Algumas destas habilidades são mais características dos prospectores, enquanto outras são dos defensores.

Os prospectores procuram manter o ajuste entre os ambientes interno e externo e ser flexíveis (MORGAN; STRONG; MCGUINNES, 2003). Aprendizado e flexibilidade refletem sua necessidade para desenvolver recursos estratégicos capazes de gerar agilidade, pró-atividade e agressividade (SLATER; NARVER, 1993). Por outro lado, as organizações defensoras, para manterem um nicho seguro em um mercado estável, focam no controle, sobretudo no de custos (HUGHES; MORGAN, 2008).

Assim, as estruturas de conhecimento dos prospectores diferem dos defensores não simplesmente porque eles atendem a um domínio de mercado mais amplo e dinâmico, mas porque combinam com um foco na flexibilidade dos processos internos, enquanto os defensores o fazem no monitoramento do ambiente com ênfase no foco interno, na eficiência (KABANOFF; BROWN, 2008).

Os analistas, segundo Miles e Snow (1978), precisam desenvolver a gestão para garantir que processos e estrutura organizacional suportem, ao mesmo tempo, áreas de operação dinâmicas e estáveis.
Para este tipo estratégico, os autores sustentam que é necessário um sistema de administração que garanta o equilíbrio entre a flexibilidade e o controle, ou seja, ao mesmo tempo que se deve possuir planejamento de marketing e produção para mercados sob seu domínio, também deve concentrar-se no desenvolvimento de novos produtos e mercados. Diante do exposto, não é possível afirmar de que as capacidades de administração são mais enfatizadas por determinado comportamento estratégico em detrimento dos demais, o que permite formular a quinta hipótese:

- H5: as capacidades de administração não variam entre os comportamentos estratégicos das organizações.

\section{Metodologia}

O estudo realizado teve uma abordagem qualiquantitativa. O método adotado para a pesquisa qualitativa foi o focus group. O ponto de partida para a definição dos recursos e capacidades pesquisados foi o estudo de Desarbo et al. (2005), que é composto um por conjunto de cinco construtos com variáveis voltadas para a indústria. Pretendeu-se, com a realização do grupo focal, adequar as variáveis que compõem cada construto à realidade do setor do comércio de material de construção.

Para a realização do focus group a amostra foi não probabilística, intencional, envolvendo a seleção dos membros de amostra a partir de julgamento dos pesquisadores, supondo que eles representam a população-alvo, porém não sendo necessariamente representativos (HAIR JUNIOR et al., 2005). Nessa condição, a amostra foi composta por 6 membros, associados à Associação dos Comerciantes de Materiais de Construção de Joinville (ACOMAC) e proprietários e/ou gerentes das lojas de material de construção de diferentes portes. A escolha de gestores deveu-se ao fato de que são os principais tomadores de decisão em suas organizações e possuem ampla experiência no ramo de atuação, representantes de empresas de porte variados, para atender às especificidades que possam existir entre o tamanho dos empreendimentos.

A sessão do grupo focal foi efetuada em setembro de 2009 e teve uma duração aproximada de 1 hora e 40 minutos. A sessão foi gravada com o consentimento dos participantes e seu conteúdo transcrito. Os dados coletados foram processados a partir da análise de conteúdo, que valoriza a descrição numérica dos dados (OLIVEIRA; FREITAS, 2006). E, a partir dos resultados obtidos, relacionaram-se os recursos e capacidades considerados estratégicos pelos participantes, que serviram de base para uma parte da etapa quantitativa deste estudo.

O método usado na segunda fase da pesquisa foi o levantamento ou survey, que envolveu todas as 
lojas de materiais de construção de Joinville, Santa Catarina, associadas à ACOMAC, para as quais foi enviado, por correio eletrônico, ou entregues, como material impresso, um questionário autoaplicável. Das 124 empresas que receberam questionários só 74 o retornaram, mas, após a verificação do preenchimento, quatro foram descartados, pelo que o estudo foi realizado com apenas 70 , representando $56,5 \%$ da população. O instrumento final (Apêndice A) contém três partes distintas.

A primeira, constituída por questões fechadas de múltipla escolha para qualificar o respondente e a sua organização. A segunda, composta por questões com escala intervalar de 1 a 10 , utilizada para mensurar o grau de importância dos recursos e capacidades considerados necessários à obtenção de vantagem competitiva pelos respondentes. Esta etapa foi elaborada a partir do focus group realizado para identificar os recursos e capacidades. E a terceira, construída com questões fechadas com o objetivo de identificar o comportamento estratégico adotado pela organização, segundo a tipologia de Miles e Snow (1978). Para isso, foi aplicada uma adaptação do questionário de Conant, Mokwa e Varadarajan (1990), com 11 questões.

O critério de classificação das organizações conforme o tipo estratégico, ou seja, defensora, prospectora, analista ou reativa, foi o mesmo de Conant, Mokwa e Varadarajan (1990) que depende da quantidade de respostas dada a cada tipologia. $\mathrm{O}$ maior número de respostas representa o tipo estratégico da organização e, nos casos de empate entre o número de questões, o critério estabelece que, se ocorrer entre o comportamento estratégico defensivo, prospector e/ ou analista, o resultado classificar-se-á como analista, enquanto que, se o empate envolver o comportamento reativo, a organização considerar-se-á reativa.

Como o questionário foi elaborado a partir das contribuições dos participantes do focus group, dispensou-se o pré-teste, já que o objetivo da sua realização foi justamente construir as questões sobre as capacidades e recursos conforme a realidade das Lojas de Material de Construção de Joinville numa linguagem adequada ao entendimento dos respondentes. Os dados coletados foram organizados numa planilha eletrônica Excel e a análise dos dados foi realizada com o software Statistica 6.0, empregando-se técnicas de análise de variância - Anova e de análise de componentes principais - ACP.

A Anova foi realizada confrontando as médias aritméticas de cada um dos cinco construtos pesquisados - capacidade de orientação ao mercado, marketing, tecnologia da informação, tecnológica e administração. Os respondentes atribuíram nota na escala 1 a 10 às capacidades e recursos de cada construto, em que o valor 1 representava muito abaixo dos três principais concorrentes e a nota 10 , muito melhor do que os três principais concorrentes. Previamente à realização da Anova, foram avaliados os pressupostos para seu uso. Empregou-se o teste de Shapiro-Wilks para verificar a normalidade dos resíduos e o teste de Levene para aferir sua homocedasticidade, além de efetuar uma análise gráfica sobre a independência dos resíduos. Os cinco construtos estudados apresentaram normalidade com uma significância de 5\% e, no teste de Levene, a Capacidade de Orientação ao Mercado só mostrou homogeneidade da variância a $1 \%$, pelo que foi refeito depois da eliminação dos dados espúrios (outliers). Nesta condição, o valor da significância do resultado, o valor $\mathrm{p}$, foi maior do que 0,05 corroborando a homocedasticidade. A independência também foi confirmada.

A análise exploratória multivariada de componentes principais foi aplicada a partir da matriz de correlações lineares de Pearson, utilizando as cinco capacidades como variáveis ativas e os comportamentos estratégicos como suplementares ou ilustrativas.

\section{Análise dos dados e resultados da pesquisa}

As análises dos dados levantados mostram que o comportamento estratégico dominante entre as lojas de material de construção filiadas à ACOMAC em Joinville (Tabela 1) é o defensivo, indicando, segundo Miles e Snow (1978), que as empresas procuram manter seu domínio de mercado, ao invés de procurarem inovar em seus serviços. Em segundo lugar, ficaram as empresas com comportamento reativo. Os mesmos autores citam que, em um ambiente competitivo, uma empresa não poderá ficar para sempre no comportamento reativo. Deverá, para poder se manter no mercado, construir uma estratégia consistente, já que esse tipo estratégico é considerado a ausência de estratégia clara.

O resultado obtido difere de outros estudos. Por exemplo, Cancellier e Blageski Júnior (2009) encontram um predomínio de prospectores, seguidos de defensores, analistas e reativos, enquanto Teixeira, Rossetto e Carvalho (2009) e Di Benedetto e Song (2003) observaram também um predomínio de

Tabela 1. Comportamento estratégico das lojas de material de construção.

\begin{tabular}{ccc}
\hline $\begin{array}{c}\text { Comportamento } \\
\text { estratégico }\end{array}$ & Frequência & $\begin{array}{c}\text { Frequência } \\
\text { relativa }\end{array}$ \\
\hline Analista & 14 & $20,00 \%$ \\
Defensor & 24 & $34,29 \%$ \\
Prospector & 13 & $18,57 \%$ \\
Reativo & 19 & $27,14 \%$ \\
Total & 70 & $100,00 \%$ \\
\hline
\end{tabular}

Fonte: Pesquisa de campo (2009). 
prospectores, porém seguidos por analistas e somente depois por defensores e reativos. Já os analistas, defensores e prospectores, respectivamente, predominaram nos estudos de Gulini (2005) e AragónSánchez e Sánchez-Marín (2005). Desarbo et al. (2006) também encontram um predomínio de analistas, porém os prospectores ficaram em segundo lugar, seguidos pelos defensores e reativos.

Deve-se ressaltar que a diferença entre os resultados pode estar associada ao perfil e segmento das empresas pesquisadas. Mesmo em estudos com empresas de igual porte, o resultado é diferente. Assim, Gimenez et al. (1999), ao pesquisar pequenas empresas, encontraram predominância de analistas, seguidos por prospectores, reativos e defensores.

\subsection{Teste das hipóteses}

As hipóteses submetidas à prova foram testadas por meio da análise de variância, cujos resultados se apresentam na Tabela 2.

Contrário a outros estudos (MCDANIEL; KOLARI, 1987; DI BENEDETTO; SONG, 2003; DESARBO et al., 2005; 2006), na primeira hipótese testada, os prospectores foram os que tiveram a menor média, enquanto os analistas a maior. Entretanto, sendo $\mathrm{p}=0,428$, não houve diferença significativa para o efeito capacidade tecnológica na comparação simultânea dos comportamentos estratégicos. Isto é, não há evidência de que entre as lojas de material de construção de Joinville exista diferença no nível dessa capacidade em relação ao comportamento estratégico adotado.

Na segunda hipótese, os prospectores apresentaram a maior média entre todos os comportamentos estratégicos, entretanto a diferença não foi significativa, pois $\mathrm{p}=0,576$. Portanto, a segunda hipótese também deve ser aceita, mostrando que não há, entre as lojas de material de construção, diferença significativa no uso da tecnologia da informação, em conformidade com o tipo estratégico. O resultado apresentado é coerente com a pesquisa de Desarbo et al. (2006), pois apesar da maior pontuação dos prospectores em relação aos demais tipos estratégicos, esses autores não comprovaram significância estatística. Por outro lado, não se confirmou o relatado nos estudos de
Aragón-Sánchez e Sánchez-Marín (2005) e de Di Benedetto e Song (2003), nos quais os prospectores tiveram uma maior capacidade de tecnologia da informação do que os analistas e os defensores. O resultado também não confirma o estudo de Song, Di Benedetto e Nason (2007), no qual se mostra que os prospectores possuem maior capacidade de TI do que os defensores.

A tendência de os defensores terem uma capacidade de orientação ao mercado maior do que os demais comportamentos (DI BENEDETTO; SONG, 2003; DESARBO et al., 2005) não se concretizou na amostra estudada. Apesar de o tipo estratégico defensor possuir média superior aos demais tipos, não há diferença significativa entre as médias $(\mathrm{p}=0,553)$, o que confirma a terceira hipótese formulada de que não há diferença para o efeito tipos estratégicos quanto à contrastação simultânea da capacidade de orientação ao mercado. O resultado corrobora o estudo de Song, Di Benedetto e Nason (2007), em que a diferença entre defensores e analistas não foi significativa e com o estudo de Desarbo et al. (2006), em que, apesar de os defensores apresentarem médias maiores, não foram significativas em relação aos demais tipos.

Contrário a outros estudos (SONG; DI BENEDETTO; NASON, 2003; DI BENEDETTO; SONG, 2003; SONG; DI BENEDETTO; NASON, 2007; DESARBO et al., 2006), o resultado da quarta hipótese demonstrou que os analistas possuem uma média maior para a capacidade de marketing. Porém, como $\mathrm{p}=0,363$ não se manifesta significativa em relação às médias dos demais comportamentos estratégicos, confirma a quarta hipótese de que não há diferença entre as capacidades de marketing.

Apesar de existirem valores distintos entre as médias da capacidade de administração, com superioridade de analistas e prospectores, elas não são significativamente diferentes entre si $(\mathrm{p}=0,197)$, admitindo-se a igualdade das médias relativas à capacidade de administração para os quatro comportamentos estratégicos. O resultado para as lojas de material de construção em Joinville é igual ao apresentado no estudo de Desarbo et al. (2006), que, embora apresente os reativos com a maior capacidade de administração, o teste de comparação de médias não foi significativo. Por outra parte, o resultado, se

Tabela 2. Resultado da análise de variância.

\begin{tabular}{llcccccc}
\hline \multirow{2}{*}{ Hipótese } & \multirow{2}{*}{ Capacidade } & \multicolumn{4}{c}{ Médias } & \multicolumn{3}{c}{ Estatística } & p \\
\cline { 3 - 7 } & & Analista & Defensor & Prospector & Reativo & F & $(\alpha=\mathbf{0 , 0 5})$ \\
\hline H1 & Tecnológica & 8,39 & 7,92 & 7,82 & 7,89 & 0,9369 & 0,4279 \\
H2 & TI & 6,94 & 6,79 & 7,13 & 6,30 & 0,6657 & 0,5761 \\
H3 & Orientação ao mercado & 7,63 & 8,07 & 7,81 & 7,64 & 0,7068 & 0,5533 \\
H4 & Marketing & 7,34 & 7,01 & 7,02 & 6,56 & 1,0813 & 0,3632 \\
H5 & Administração & 7,88 & 7,04 & 7,81 & 7,11 & 1,6035 & 0,1970 \\
\hline
\end{tabular}

Fonte: Pesquisa de campo (2009). 
comparado ao relatado por Desarbo et al. (2005), que encontraram maiores médias nos grupos formados por prospectores e analistas, mostra-se diferente, pois aqueles autores encontraram diferenças significativas para as comparações com as médias dos outros comportamentos estratégicos.

Divergências entre os resultados desta pesquisa com os expostos nos diversos artigos considerados podem ser devidas às diferenças culturais, quando se trata de países diferentes, ou ao segmento estudado, dentre outras. Mas, como nenhum estudo semelhante a este foi encontrado no Brasil, não foi possível efetuar comparações mais apropriadas. De qualquer modo, foi evidenciado que o segmento varejista de material de construção na cidade de Joinville-SC não se preocupa em alinhar seus recursos e capacidades ao comportamento estratégico adotado.

O cenário apresentado indica que as empresas estudadas podem perder a possibilidade de geração de vantagem competitiva (PETERAF; BARNEY, 2003), ao não explorar os recursos e as capacidades que melhor respondam ao comportamento estratégico predominante (DESARBO et al., 2006; SONG; DI BENEDETTO; NASON, 2007; HUGHES; MORGAN, 2008) . Segundo Menon et al. (1999) e Barney (2001), a situação de criar uma estratégia sem os recursos necessários pode resultar, ao contrário do desejado, no prejuízo do desempenho da empresa.

\subsection{Associação entre comportamento estratégico e capacidades da empresa}

Por meio da análise de componentes principais buscou-se entender a associação entre o comportamento estratégico e as capacidades das lojas de material de construção. Para avaliar quantos autovalores deviam ser considerados, utilizou-se o critério de Cattell (1966), verificando-se que a curva do decréscimo dos autovalores se estabiliza no segundo fator, com a recuperação de 80,6\% da variância. Assim, a interpretação foi realizada a partir do plano fatorial principal.
A Tabela 3 apresenta a correlação entre as cinco capacidades e os comportamentos estratégicos.

Todas as capacidades são correlacionadas entre si muito significativamente, sendo os maiores valores do coeficiente entre as capacidades de administração e tecnológica, com 0,729 e entre a orientação ao mercado e a capacidade de marketing, com 0,706. Tem-se na capacidade tecnológica uma aliada para a realização de uma boa gestão do negócio, que permita o acesso à informação confiável e em tempo real, para melhorar o processo de tomada de decisão, enquanto a capacidade de marketing fornece subsídios para que a empresa possa ter uma orientação ao mercado, concretizada pela fidelização com os clientes e relações duradouras com fornecedores.

Quanto à correlação entre comportamentos estratégicos e capacidades, percebe-se que o comportamento reativo tem correlação negativa com todas elas, sendo com tecnologia da informação $(-0,201)$ e com administração $(-0,209)$ os maiores valores negativos com significância a 10\%. Situação semelhante ocorre com os defensores, possuindo correlação negativa com as capacidades, sendo com a capacidade de administração, embora não significativo, o maior valor negativo $(-0,146)$.

Os prospectores possuem a maior correlação entre comportamentos e capacidades, alcançando seu coeficiente 0,255 com a capacidade de administração ( $\mathrm{p}<0,05)$. Já os analistas têm o segundo maior valor, atingindo 0,203 , quando correlacionados à capacidade tecnológica $(\mathrm{p}<0,10)$. Cabe salientar ainda que tanto prospectores quanto analistas tiveram correlações positivas com as capacidades consideradas, embora a maioria não apresente significância estatística.

A Figura 1 permite visualizar o relacionamento entre as variáveis na projeção dos vectores que as representam no plano do fator 1 versus fator 2 da ACP. Os ângulos agudos entre as capacidades manifestam a existência de correlações positivas entre elas, destacando-se que é possível diferenciar um subgrupo formado pelas capacidades de marketing e orientação ao mercado, disposto sobre o quadrante III, de outro formado pelas outras três, localizado no quadrante II.

Tabela 3. Correlação entre as capacidades e os tipos de comportamentos estratégicos.

\begin{tabular}{lccccccccc}
\hline Capacidade-comportamento & MKT & OM & TI & TEC & ADM & A & D & P & R \\
\hline Marketing (MKT) & - & 0,706 & 0,502 & 0,656 & 0,631 & 0,063 & $-0,052$ & 0,107 & $-0,092$ \\
Orientação de Mercado (OM) & $* * *$ & - & 0,484 & 0,615 & 0,535 & 0,103 & $-0,035$ & 0,057 & $-0,106$ \\
Tecnologia da Informação (TI) & $* * *$ & $* * *$ & - & 0,594 & 0,603 & 0,081 & $-0,003$ & 0,117 & $-0,201$ \\
Tecnológica (TEC) & $* * *$ & $* * *$ & $* * *$ & - & 0,729 & 0,203 & $-0,099$ & 0,002 & $-0,041$ \\
Administração (ADM) & $* * *$ & $* * *$ & $* * *$ & $* * *$ & - & 0,177 & $-0,146$ & 0,255 & $-0,209$ \\
Analista (A) & ns & ns & ns & $*$ & ns & - & $-0,593$ & 0,099 & $-0,122$ \\
Defensor (D) & $\mathrm{ns}$ & $\mathrm{ns}$ & $\mathrm{ns}$ & $\mathrm{ns}$ & $\mathrm{ns}$ & $* * *$ & - & $-0,597$ & $-0,410$ \\
Prospector (P) & $\mathrm{ns}$ & $\mathrm{ns}$ & $\mathrm{ns}$ & $\mathrm{ns}$ & $* *$ & $\mathrm{~ns}$ & $* * *$ & - & $-0,195$ \\
Reativo (R) & $\mathrm{ns}$ & $\mathrm{ns}$ & $*$ & $\mathrm{~ns}$ & $\mathrm{~ns}$ & $*$ & $* * *$ & $\mathrm{~ns}$ & - \\
\hline
\end{tabular}

$* \mathrm{p}<0,10 ; * * \mathrm{p}<0,05 ; * * * \mathrm{p}<0,01 ; \mathrm{ns}=$ não significativo. Fonte: Pesquisa de campo (2009). 
As maiores correlações positivas entre as variáveis, sejam suplementares ou ativas, geram ângulos mais agudos, chegando a serem retos quando há falta de correlação ou obtusos na condição de correlações negativas.

A Figura demonstra que há correlação positiva das empresas prospectoras e analistas com as capacidades, enquanto as defensoras e reativas possuem correlação negativa. Isto pode ser interpretado do seguinte modo: havendo maior investimento em tecnologia da informação e na capacidade de administração, como controle de custos, gestão de pessoas, previsão de receitas, planejamento de marketing, etc., menor a chance de o comportamento ser reativo.

Sendo assim, quando aumenta a ênfase dada às capacidades de tecnologia da informação e de administração diminuem as empresas com comportamento estratégico reativo. Também se pode dizer que as empresas reativas não investem em tecnologia da informação e mantêm apenas o mínimo necessário para garantir o funcionamento da empresa.

A mesma lógica poderia ser utilizada para os defensores, mas como estes têm correlação negativa com todos os outros comportamentos, tornam necessário incluir mais um fator para entender seu relacionamento com as capacidades. Na projeção das variáveis no plano do fator 3 versus fator 2 (Figura 2), observa-se que os defensores mostram relação tanto com a capacidade de tecnologia de informação quanto com a orientação de mercado.

A posição desse tipo estratégico na figura é coerente com a busca e manutenção de uma posição segura e estável no mercado, que inclui, dentre outras ações, por exemplo, a fidelização dos clientes e esta pressupõe

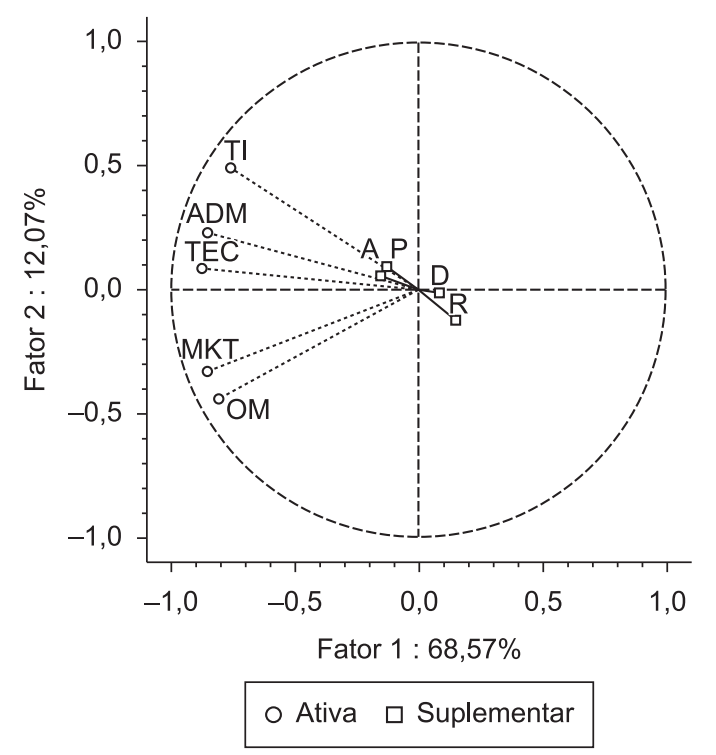

Figura 1. Análise de Componentes Principais. Fator 1 vs. Fator 2. Fonte: Pesquisa de campo (2009). a existência de sistema de informação que garanta o conhecimento dos hábitos dos consumidores e assim proporcione sua retenção.

Para analisar melhor a correlação dos comportamentos estratégicos em relação às capacidades da empresa, fez-se a análise individual de cada comportamento em relação às capacidades, iniciando-se pelo reativo.

A partir da Tabela 3, percebe-se que todas as correlações dos reativos com as capacidades são negativas, sendo as maiores correlações em relação à tecnologia da informação e administração. O resultado confirma a afirmação de Miles et al. (1978) de que os reativos não possuem um padrão consistente e estável de ajuste ao seu ambiente. Com isso, falta-lhes um conjunto de mecanismos de resposta que possa adequadamente garantir a organização diante de uma mudança ambiental. Sem investir em nenhuma capacidade, os reativos apenas respondem aos estímulos. Miles et al. (1978) chamam isso de uma instabilidade quase perpétua.

Outro comportamento que apresentou apenas correlação negativa foi o defensor, sendo a maior delas em relação à capacidade de administração. Considerado um tipo estratégico consistente em seu domínio, os defensores não apresentaram nenhuma correlação positiva. Significa dizer que os defensores não estão alinhados às capacidades que podem contribuir para a geração de vantagem competitiva. Somados, defensores e reativos totalizam $61,43 \%$ dos respondentes e não há entre eles um ajuste entre o tipo estratégico e os recursos necessários para a sua implementação. Barney (2001) afirma que uma estratégia é criada para ajustar a organização ao seu ambiente e criá-la sem esta capacidade de

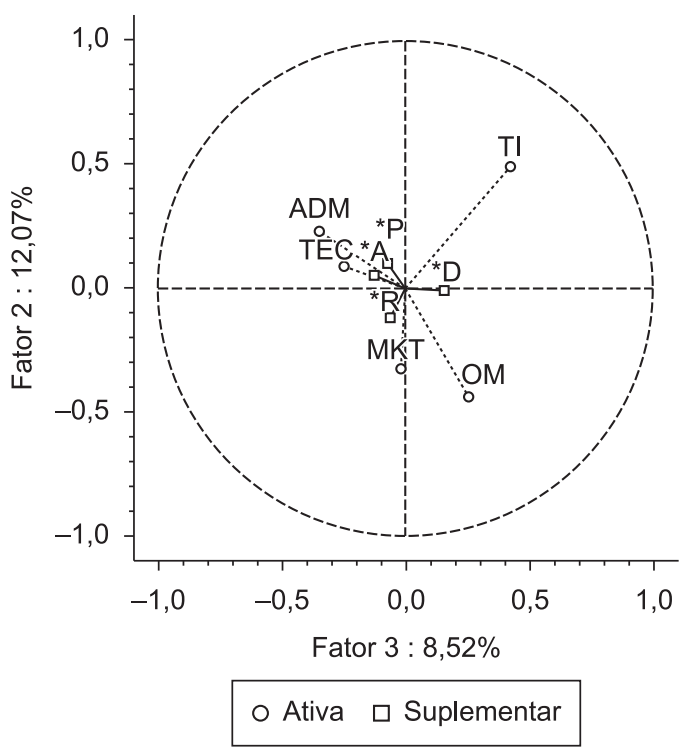

Figura 2. Análise de Componentes Principais. Fator 3 vs. Fator 2. Fonte: Pesquisa de campo (2009). 
implementação pode ser prejudicial ao desempenho. Neste sentido, Hughes e Morgan (2008) afirmam que as organizações com melhor desempenho possuem maior ajuste entre seus recursos e sua estratégia.

Apesar de não ter correlações altas, os analistas, a diferença dos reativos e defensores apresentam correlação positiva, principalmente com as capacidades tecnológica e de administração. Enquanto a capacidade tecnológica é considerada mais importante para os prospectores (SONG; DI BENEDETTO; NASON, 2007), a de administração é importante tanto para prospectores quanto para defensores (MORGAN; STRONG; MCGUINNES, 2003; SLATER; NARVER, 1993; HUGHES; MORGAN, 2008), contemplando o que afirmam Miles e Snow (1978), já que o analista está situado entre aqueles dois comportamentos. Entretanto, o resultado também demonstra uma ausência de ajuste apropriado entre a estratégia e os recursos e capacidades necessários à sua implementação que proporcione um desempenho acima da média (HUGHES; MORGAN, 2008), pois a correlação é baixa com as capacidades tecnológica $(\mathrm{p}<0,10)$ e de administração $(\mathrm{p}<0,15)$ e não significativa com as capacidades de marketing, tecnologia da informação e orientação ao mercado.

O quarto e último comportamento estratégico, prospector, foi o que obteve a maior correlação entre os comportamentos com uma das capacidades pesquisadas - capacidade de administração, com 0,255. Mas, é importante salientar que não há correlação significativa entre prospectores e as capacidades de orientação ao mercado e tecnológica. Se a orientação ao mercado é considerada como uma capacidade dos defensores, como foi expresso pelo fator 3 da ACP, a tecnológica está vinculada aos prospectores, por sua necessidade de criar novos produtos e serviços, explorar novos mercados, enfim ser o primeiro a apresentar novidades (SONG; DI BENEDETTO; NASON, 2007). Tal resultado reforça a consideração anteriormente feita de que não há, no segmento considerado, lojas de materiais de construção, mesmo entre os comportamentos dos defensores, analistas e prospectores, um ajuste conspícuo da estratégia aos recursos e capacidades que proporcionem a geração de vantagem competitiva sustentável (BARNEY, 2001; HUGHES; MORGAN, 2008).

\section{Considerações finais}

A perenidade de uma organização passa pela clareza de sua estratégia (MILES; SNOW, 1978). Saber aonde se quer chegar e dispor dos recursos necessários para atingir estes objetivos é uma tarefa muitas vezes difícil de ser realizada. Afinal, a capacidade de implementação da estratégia é, em si mesma, um recurso estratégico (BARNEY, 2001). Portanto, a inadequação na escolha ou definição de uma estratégia para se ajustar às características do ambiente pode gerar um desempenho abaixo do esperado (HUGHES; MORGAN, 2008).

O estudo mostrou que o comportamento estratégico predominante entre as empresas pesquisadas foi o defensor. É, portanto, um perfil de empresas que monitoram pouco o ambiente, não investem no desenvolvimento de novos produtos e serviços, mas procuram manter o domínio de seu mercado por meio da qualidade dos produtos e dos serviços. Já o menor grupo foi o de empresas prospectoras, indicando que o segmento não é gerador de novos serviços e pouco investe em novas tecnologias e em tecnologia da informação.

Mas o que chama a atenção é que $27,14 \%$ das empresas são reativas, indicando não possuírem clareza quanto às suas estratégias. Além disso, quando considerado o ciclo adaptativo de Miles e Snow, os reativos possuem os maiores percentuais nos três problemas de adaptação organizacional.

As cinco hipóteses testadas foram confirmadas, evidenciando que as capacidades tecnológicas, de tecnologia da informação, de marketing, orientação ao mercado e administrativa não variam conforme o comportamento estratégico. O resultado, a exemplo de outros estudos, não permite ser conclusivo quanto à ênfase dada às capacidades e recursos por cada um dos comportamentos estratégicos. O próprio comportamento reativo, contrariando a teoria, obteve média superior à dos prospectores em relação às capacidades tecnológicas, embora não mostrasse significância, entretanto essa capacidade tem grande importância para os prospectores, por seu estilo inovador, tanto na criação de novos produtos, quanto na abertura de novos mercados.

Importante destacar que os reativos obtiveram as menores médias nas capacidades de tecnologia da informação e marketing. Como o comportamento estratégico reativo é considerado a inconsistência de estratégia, processos e estrutura, a situação é relevante, já que $63,16 \%$ delas atuam há mais de 10 anos e podem não estar dando a devida atenção às mudanças ambientais. Correm o risco de não interagirem constante e adequadamente com o ambiente e, em consequência, serem eliminadas do mercado.

A análise de componentes principais demonstrou, em relação aos reativos, uma correlação negativa com todas as capacidades, sendo em maior grau com as capacidades de tecnologia da informação e de administração - esta última foi a maior correlação negativa dentre todas. O resultado confirma o modelo de Miles e Snow quanto a este tipo estratégico. Porém, a correlação dos defensores também foi negativa com todas as capacidades, sendo em maior grau com a capacidade de administração. Como é um tipo estratégico consistente em suas ações, era de se esperar uma correlação positiva dos defensores com 
as capacidades, particularmente com a orientação ao mercado, o que se pode verificar pela ACP.

Por outro lado, os outros dois comportamentos analista e prospector - tiveram correlação positiva com todas as capacidades, sendo as maiores dos analistas com as capacidades de tecnologia e administração, enquanto que para os prospectores com a capacidade de administração e de tecnologia da informação. Conclui-se que os prospectores e analistas dão maior ênfase às questões que compõem estas capacidades para atingir os objetivos de seus negócios.

Como os analistas situam-se entre os prospectores e os defensores, as capacidades tecnológicas e de administração são importantes, pois enquanto àquela fornece condições para monitorar o ambiente, esta permite que os analistas desenvolvam habilidades de controle de custos e tenham competência financeira e da gestão de recursos humanos para garantir a prestação de atendimento com qualidade e preservar seu domínio de mercado.

Por sua vez, os prospectores, que se caracterizam por serem os primeiros no lançamento de produtos e/ou na conquista de mercados, aproveitam-se da tecnologia da informação para facilitar a criação de conhecimento de mercado, assim como para desenvolver a comunicação interna e externa. Mas, para a concretização de seus objetivos, necessitam de capacidade de administração que lhes garanta a gestão de recursos humanos, a competência financeira e do planejamento de marketing, além de uma gestão participativa, que privilegie a inovação e a criatividade.

O presente estudo demonstra a possibilidade de crescimento do segmento, caso haja um trabalho coordenado de elaboração das estratégias e adequação dos processos e estrutura das empresas que possibilite o aproveitamento adequado dos recursos e capacidades. Além disso, é importante o monitoramento do ambiente para manter os produtos e serviços coerentes com a demanda do mercado. Para isto, dois desafios primordiais no segmento devem ser superados: a redução do número de empresas reativas e a adequação dos recursos e capacidades aos comportamentos estratégicos das empresas, o que possibilitaria a geração de vantagem competitiva. Este último aspecto é provavelmente a maior implicação gerencial percebida na pesquisa.

Para a RBV, as organizações precisam investir e explorar suas capacidades para capitalizá-las, melhorando seu desempenho e gerando vantagem competitiva sustentável. No caso dos defensores, que formam o maior grupo, investir no aprimoramento das capacidades que aumentam as chances de manutenção do domínio de mercado torna-se uma tarefa fundamental, para permitir o alinhamento entre estratégia, estrutura e processos.

Quanto às limitações, deve se destacar que não foi possível ter acesso aos dados de desempenho das empresas, o que impossibilitou relacionar comportamento estratégico, recursos e desempenho. Outra limitação está relacionada à impossibilidade de generalização, tendo em vista que a pesquisa foi aplicada apenas aos associados da ACOMAC de Joinville e, portanto, os resultados aplicam-se apenas ao conjunto estudado, não podendo ser extrapolados para outras empresas não associadas ou que pertençam a outras regiões do País.

Por fim, sugere-se, em trabalhos futuros, incluir o desempenho para seu estudo em relação ao comportamento estratégico, recursos e capacidades, com a finalidade de verificar se as empresas que melhor ajustam os recursos ao seu comportamento possuem desempenho superior. Pela falta de mais estudos que associem o comportamento estratégico aos recursos no Brasil, novas pesquisas poderão verificar se os resultados obtidos são apenas peculiares ao setor estudado.

\section{Referências}

ANDRETTI, A. P. Ambiente organizacional, comportamento estratégico e desempenho empresarial: estudo do setor hoteleiro de Macaé/RJ. 2008. 130 f. Dissertação (Mestrado em Administração)Universidade do Vale do Itajaí, Biguaçu, 2008.

ANDREWS, R. et al. Strategy formulation, strategy content and performance. Public Management Review, v. 11, n. 1, p. 1-22, 2009.

ARAGÓN-SÁNCHEZ, A.; SÁNCHEZ-MARÍN, G. Strategic orientation, management characteristics, and performance: a study of Spanish SMEs. Journal of Business Management, v. 43, n. 3, p. 287-308, 2005.

BAILEY, A.; JOHNSON, G. Strategy development processes: a configurational approach. Academy of Management Journal, p. 2-6, 1995.

BANDEIRA-DE-MELLO, R.; CUNHA, C. J. C. A. A natureza e a dinâmica das capacidades organizacionais no contexto brasileiro: uma agenda para pesquisas sobre a vantagem competitiva das empresas brasileiras. In: ENCONTRO DA ANPAD, 25., 2001, Campinas. Anais... Campinas: ANPAD, 2001.

BARNEY, J. B. Strategic factor markets: expectations, luck and business strategy. Management Science, v. 32, n. 10, p. 1231-1241, 1986.

BARNEY, J. B. Firm resources and sustained competitive advantage. Journal of Management, v. 7, n. 1, p. 99-120, 1991.

BARNEY, J. B. Is the resource-based "view" a useful perspective for strategic management research? Yes. Academy of Management Review, v. 26, n. 1, p. 41-56, 2001.

BARNEY, J. B.; HESTERLY, W. S. Administração estratégica e vantagem competitiva. São Paulo: Pearson Prentice Hall, 2007.

CANCELLIER, E. L. P. L.; BLAGESKI JUNIOR, E. J. Comportamento estratégico, monitoramento do ambiente, características organizacionais e desempenho em empresas de pequeno porte. In: ENCONTRO DA ANPAD, 33., 2009, São Paulo. Anais... São Paulo: ANPAD, 2009. 
CATTELL, R. B. The scree test for the number of factors. Multivariate Behavioral Research, v. 1, p. 245-276, 1966.

CONANT, J. S.; MOKWA, M. P.; VARADARAJAN, P. R. Strategic types, distinctive marketing competencies and organizational performance: a multiple measures-based study. Strategic Management Journal, v. 11, n. 5, p. 365-383, 1990.

CRUBELlATE, J. M.; PASCUCCI, L.; GRAVE, P. S. Contribuições para uma visão baseada em recursos legítimos. Revista de Administração de Empresas, v. 48, n. 4, p. 8-19, 2008.

DESARBO, W. S. et al. Revisiting the Miles and Snow strategic framework: uncovering interrelationships between strategic types, capabilities, environmental uncertainty, and firm performance. Strategic Management Journal, v. 26, p. 47-74, 2005.

DESARBO, W. S. et al. Identifying sources of heterogeneity for empirically deriving strategic types: a constrained finite-mixture structural-equation methodology. Management Science, v. 52, n. 6, p. 909- 924, 2006.

DIERICKX, I.; COOL, K. Asset stock accumulation and sustainability of competitive advantage. Management Science, v. 33, n. 12, 1989.

DI BENEDETTO, C. A.; SONG, M. The relationship between strategic type and firm capabilities in Chinese firms. International Marketing Review, v. 20, n. 5, p. 514-533, 2003.

FOSS, K.; FOSS, N. J. Resources and transaction costs: how property rights economics furthers the resourcebased view. Strategic Management Journal, v. 26, p. 541-553, 2005.

GIMENEZ, F. A. P. et al. Estratégia em pequenas empresas: uma aplicação do modelo de Miles e Snow. Revista de Administração Contemporânea, v. 3, n. 2, p. 53-74, 1999.

GULINI, P. L. Ambiente organizacional, comportamento estratégico e desempenho empresarial: um estudo no setor de provedores de internet de Santa Catarina. 2005. 160 f. Dissertação (Mestrado em Administração)Universidade do Vale do Itajaí, Biguaçu, 2005.

HAIR JUNIOR., J. F. et al. Fundamentos de métodos de pesquisa em administração. Porto Alegre: Bookman, 2005.

HAMBRICK, D. C. On the staying power of defenders, analyzers, and prospectors. Academy of Management Executive, v. 17, n. 4, 2003.

HUGHES, P.; MORGAN, R. E. Fitting strategic resources with product-market strategy: performance implications. Journal of Business Research, v. 61, p. 323-331, 2008.

KABANOFF, B.; BROWN, S. Knowledge structures of prospectors, analyzers, and defenders: content, structure, stability, and performance. Strategic Management Journal, v. 29, p. 149-171, 2008.

LEONARD-BARTON, D. Core capabilities and core rigidities: a paradox in managing new product development. Strategic Management Journal, v. 13, p. 111-125, 1992.

MALONE, K. et al. Cloning an industry: strategy typologies of Shangai biotechnology companies. Journal of Commercial Biotechnology, v. 14, n. 1, p. 31-42, 2008.

MCDANIEL, S. W; KOLARI, J. W. Marketing strategy implications of the Miles and Snow strategic typology. Journal of Marketing, v. 51, p. 19-30, 1987.

MENON, A. et al. Antecedents and consequences of marketing strategy making: a model and test. Journal of Marketing, v. 63, p. 18-40, 1999.
MILES, R. E. et al. Organizational strategy, structure, and process. Academy of Management Review, v. 3, n. 3, p. 546-562, 1978.

MILES, R. E.; SNOW, C. C. Organizational strategy, structure, and process. New York: McGraw-Hill, 1978.

MINTZBERG, H. Strategy-making in three modes. California Management Review, v. 16, n. 2, p. 44-53, 1973.

MINTZBERG, H. Crafting strategy. Harvard Business Review, v. 65, n. 4, p. 66-75, 1987.

MORGAN, R. E.; STRONG, C. A.; MCGUINNES, T. Product-market positioning and prospector strategy: an analysis of strategic patterns from the resource-based perspective. European Journal of Marketing, v. 37, n. 10, p. 1409-1439, 2003.

NAG, R.; HAMBRICK, D. C.; CHEN, M. What is strategic management, really? Inductive derivation of a consensus definition of the field. Strategic Management Journal, v. 28, p. 935-955, 2007.

OLIVEIRA, M.; FREITAS, H. Focus Group: instrumentalizando o seu planejamento. In: GODOI, C. K.; BANDEIRA-DEMELLO, R.; SILVA, A. B. (Org.). Pesquisa qualitativa em estudos organizacionais: paradigmas, estratégias e métodos. São Paulo: Saraiva, 2006.

OLSON, E. M.; SLATER, S. F.; HULT, G. T. M. The performance implications of fit among business strategy, marketing organization structure, and strategic behavior. Journal of Marketing, v. 69, p. 49-65, 2005.

PENG, M. W.; TAN, J.; TONG, T. W. Ownership types and strategic groups in an emerging economy. Journal of Management Studies, v. 41, n. 7, p. 1105-1129, 2004.

PENROSE, E. G. The theory of the growth of the firm. Nova Iorque: Wiley, 1959.

PETERAF, M. A. The cornerstones of competitive advantage: a resource-based view. Strategic Management Journal, v. 14 , n. 3, p. 179-191, 1993.

PETERAF, M. A.; BARNEY, J. B. Unraveling the resourcebased tangle. Managerial and Decision Economics, v. 24 , p. 309-323, 2003

PLESHKO, L.; NICKERSON, I. Strategic orientation, organizational structure, and the associated effects on performance in industrial firms. Academy of Strategy Management Journal, v. 7, p. 95-110, 2008.

PORTER, M. E. Estratégia competitiva: técnicas para análise de indústrias e da concorrência. 7. ed. Rio de Janeiro: Campus, 1996.

SLATER, S. F.; NARVER, J. C. Product-market strategy and performance: an analysis of the Miles and Snow strategy types. European Journal of Marketing, v. 27, n. 10 , p. 33-51, 1993.

SONG, M.; DI BENEDETTO, A.; NASON, R. W. Capabilities and financial performance: the moderating effect of strategic type. Journal Academy Marketing Science, v. 35, p. 18-34, 2007.

TEECE, D. J.; PISANO, G.; SHUEN, A. Dynamic capabilities and strategic management. Strategic Management Journal, v. 18, n. 7, p. 509-533, 1997.

TEIXEIRA, O. R. P.; ROSSETTO, C. R.; CARVALHO, C. E. A relação entre o ambiente organizacional e o comportamento estratégico no setor hoteleiro de Florianópolis - SC. Turismo Visão e Ação, v. 11, n. 2, p. 157-174, 2009.

WERNERFELT, B. A resource-based view of the firm. Strategic Management Journal, v. 5, n. 2, p. 171-180, 1984. 


\section{Apêndice A - Questionário}

Prezado (a) Senhor (a),

Com o objetivo de coletar dados para a realização de uma pesquisa sobre o Comportamento Estratégico da Empresa e os seus Recursos e Capacidades no setor varejista de material de construção, solicitamos a sua colaboração, respondendo ao questionário abaixo.

Com base nos preceitos éticos, informamos que sua participação será mantida sob sigilo, não constando seu nome ou qualquer outra informação que possa identificá-lo no relatório final ou em qualquer outra publicação que venha a ser realizada sobre esta pesquisa.

Para a perfeita utilização dos dados coletados, solicitamos que todas as perguntas sejam respondidas.

Agradecemos por sua colaboração e reiteramos a importância de sua contribuição para a construção do conhecimento na área pesquisada.

\section{A. Qualificação do respondente e da empresa}

1. Qual o seu sexo?

( ) Masculino ( ) Feminino

2. Qual a sua escolaridade?

( ) Ensino fundamental ( ) Ensino médio incompleto ( ) Ensino médio completo

( ) Superior incompleto ( ) Superior completo ( ) Pós-graduação

3. Qual a sua faixa etária?

( ) Até 18 anos ( ) De 19 a 25 anos ( ) De 26 a 35 anos

( ) De 36 a 45 anos ( ) De 46 a 55 anos ( ) Acima de 55 anos

4. Qual a sua função na empresa?

( ) Sócio-proprietário ( ) Diretor ( ) Gerente ( ) Outro. Qual?

5. Com relação ao porte, sua empresa é...

( ) Microempresa ( ) Pequena ( ) Média ( ) Grande

6. Sua empresa possui filial?

( ) Não ( ) Sim. Quantas filiais?

7. Quantos funcionários trabalham na loja (filial) que você trabalha?

( ) Até 09 ( ) De 10 a 49 ( ) De 50 a 99 ( ) De 100 a 299 ( ) Acima de 299

8. Há quanto tempo a sua empresa está no mercado?

( ) Até 5 anos ( ) De 6 a 10 anos ( ) Acima de 10 anos

\section{B. Recursos e capacidades da empresa}

9. Abaixo é apresentado um conjunto de possíveis capacidades estratégias da empresa. Por favor, avalie como você acredita que estes itens são desempenhados em sua empresa em relação a seus três principais concorrentes.

Utilize a seguinte escala: $\mathbf{1}$ = muito abaixo dos três principais concorrentes; $\mathbf{1 0}=$ muito melhor do que os três principais concorrentes.

\begin{tabular}{|c|c|c|c|c|c|c|c|c|c|c|}
\hline Capacidades de Marketing & 1 & 2 & 3 & 4 & 5 & 6 & 7 & 8 & 9 & 10 \\
\hline Conhecimento dos clientes & & & & & & & & & & \\
\hline Conhecimento dos concorrentes & & & & & & & & & & \\
\hline Integração das atividades de pré-venda, venda e pós-vend & & & & & & & & & & \\
\hline Competência para segmentar e definir os mercados de atua & & & & & & & & & & \\
\hline Eficácia da formação do preço de venda & & & & & & & & & & \\
\hline Eficácia de publicidade & & & & & & & & & & \\
\hline Competência para oferecer serviços adicionais ao cliente & & & & & & & & & & \\
\hline
\end{tabular}




\begin{tabular}{|l|c|c|c|c|c|c|c|c|c|c|}
\hline \multicolumn{1}{|c|}{ Capacidades de orientação ao mercado } & $\mathbf{1}$ & $\mathbf{2}$ & $\mathbf{3}$ & $\mathbf{4}$ & $\mathbf{5}$ & $\mathbf{6}$ & $\mathbf{7}$ & $\mathbf{8}$ & $\mathbf{9}$ & $\mathbf{1 0}$ \\
\hline Capacidade de estar em sintonia com o mercado & & & & & & & & & & \\
\hline Capacidade para reter clientes (fidelização) & & & & & & & & & \\
\hline Capacidade de criar relacionamento durável com os fornecedores & & & & & & & & & \\
\hline
\end{tabular}

\begin{tabular}{|c|c|c|c|c|c|c|c|c|c|c|}
\hline Capacidades de Tecnologia da Informação (TI) & 1 & 2 & 3 & 4 & 5 & 6 & 7 & 8 & 9 & 10 \\
\hline Sistemas de TI para facilitar a integração entre os departamentos & & & & & & & & & & \\
\hline Sistemas de TI para facilitar as informações do produto no ato da venda & & & & & & & & & & \\
\hline Sistemas de TI para facilitar a criação de conhecimento de mercado & & & & & & & & & & \\
\hline Sistemas de TI para a comunicação interna & & & & & & & & & & \\
\hline Sistemas de TI para a comunicação externa & & & & & & & & & & \\
\hline Sistemas de TI para o gerenciamento das informações & & & & & & & & & & \\
\hline
\end{tabular}

\begin{tabular}{|c|c|c|c|c|c|c|c|c|c|c|}
\hline Capacidades tecnológicas & 1 & 2 & 3 & 4 & 5 & 6 & 7 & 8 & 9 & 10 \\
\hline Capacidade de desenvolvimento de novos serviços & & & & & & & & & & \\
\hline Capacidade de acompanhar o lançamento de novos produtos & & & & & & & & & & \\
\hline Habilidade de prever mudanças tecnológicas no setor & & & & & & & & & & \\
\hline Capacidade de cumprimento de prazo de entrega & & & & & & & & & & \\
\hline Competência para entregar o produto em perfeitas condições & & & & & & & & & & \\
\hline Habilidade para prestar atendimento com qualidade & & & & & & & & & & \\
\hline
\end{tabular}

\begin{tabular}{|c|c|c|c|c|c|c|c|c|c|c|}
\hline Capacidades de administração & 1 & 2 & 3 & 4 & 5 & 6 & 7 & 8 & 9 & 10 \\
\hline Sistemas logísticos integrados & & & & & & & & & & \\
\hline Capacidade de controle de custos & & & & & & & & & & \\
\hline Competência de administração financeira & & & & & & & & & & \\
\hline $\begin{array}{l}\text { Capacidade de administração de recursos humanos } \\
\text { (recrutamento, seleção, treinamento...) }\end{array}$ & & & & & & & & & & \\
\hline Exatidão da previsão de receitas e lucratividade & & & & & & & & & & \\
\hline Processo de planejamento de marketing & & & & & & & & & & \\
\hline Capacidade de manter a equipe alinhada aos objetivos da empresa & & & & & & & & & & \\
\hline Gestão participativa & & & & & & & & & & \\
\hline
\end{tabular}

\section{Comportamento estratégico}

Nas próximas questões, assinale a alternativa que melhor expressa a sua realidade. Assinale apenas uma alternativa por questão.

10. Os serviços e produtos que são oferecidos aos nossos clientes são mais bem caracterizados como:

a. ( ) São mais inovadores e estão constantemente mudando e ampliando sua área de aplicação.

b. ( ) Alguns são bastante estáveis no mercado enquanto outros são inovadores.

c. ( ) São bem focados, relativamente estáveis e bem definidos na organização e no mercado.

d. ( ) Estão em estado de transição e são baseados em respostas a oportunidades ou ameaças do mercado ou ambiente.

11. Nossa empresa tem uma imagem no mercado de uma organização que:
a. ( ) Oferece poucos produtos/serviços, porém seletivos e de alta qualidade.
b. ( ) Adota novas ideias e inovações, mas somente após análise cuidadosa.
c. ( ) Reage às oportunidades ou ameaças de mercado para manter e reforçar nossa posição.
d. ( ) Tem reputação de ser inovadora e criativa. 
12. O tempo investido pela empresa para monitorar as mudanças e tendências no mercado pode ser mais bem descrito como sendo:
a. ( ) Extenso, a empresa está constantemente monitorando o mercado.
b. ( ) Mínimo, a empresa realmente não passa muito tempo monitorando o mercado.
c. ( ) Médio, a empresa gasta algum tempo monitorando o mercado.
d. ( ) Esporádico, às vezes a empresa gasta um bom tempo e outras vezes ela gasta pouco tempo monitorando o mercado.

13. O crescimento ou diminuição de nossa demanda é devido muito provavelmente à:
a. ( ) Nossa prática de nos concentrarmos no desenvolvimento dos mercados que já servimos.
b. ( ) Nossa prática de respondermos às pressões do mercado, correndo poucos riscos.
c. ( ) Nossa prática de entrar agressivamente em novos mercados com novos tipos de serviços/ produtos.
d. ( ) Nossa prática de nos aprofundarmos nos mercados que já servimos, enquanto adotamos novos serviços/produtos somente após uma análise cuidadosa do seu potencial.

14. Uma das metas mais importantes da empresa é a dedicação e compromisso com:
a. ( ) Manter os custos sob controle.
b. ( ) Analisar cuidadosamente nossos custos e receitas para manter os custos sob controle, seletivamente gerar novos serviços/produtos e entrar em novos mercados.
c. ( ) Garantir que pessoas, recursos e equipamentos necessários para desenvolver novos serviços/ produtos e novos mercados estejam disponíveis e acessíveis.
d. ( ) Resguardar a empresa contra ameaças críticas adotando as ações que sejam necessárias.

15. As competências e habilidades que os funcionários da empresa possuem podem ser mais bem caracterizados como:
a. ( ) Analíticas: suas habilidades os capacitam a identificar tendências e a desenvolver novos serviços/produtos e novos mercados.
b. ( ) Especializadas: suas habilidades são concentradas em poucas áreas específicas.
c. ( ) Amplas e empreendedoras: suas habilidades são diversas, flexíveis e os habilitam a mudar de forma criativa.
d. ( ) Flexível: suas habilidades estão relacionadas com as demandas de curto prazo do mercado.

16. Uma das coisas que protege nossa empresa de outros concorrentes é que nós:
a. ( ) Somos capazes de cuidadosamente analisar tendências emergentes e adotar aquelas que têm potencial comprovado.
b. ( ) Somos capazes de fazer um número limitado de coisas excepcionalmente bem.
c. ( ) Somos capazes de responder a novas tendências mesmo que, quando elas surgem, possuam apenas um potencial moderado.
d. ( ) Somos capazes de desenvolver novos serviços/produtos e novos mercados de maneira consistente.

17. O gerenciamento da empresa tende a concentrar-se em:
a. ( ) Manter uma situação segura por meio de medidas de controle de custos de qualidade.
b. ( ) Analisar oportunidades no mercado e escolher apenas aquelas que apresentam potencial, e, ao mesmo tempo, manter a situação financeira protegida.
c. ( ) Atividades ou negócios que mais necessitam de atenção em vista das oportunidades ou problemas que estão sendo enfrentados.
d. ( ) Desenvolver novos serviços ou se expandir para novos mercados ou novos segmentos de mercado.

18. A organização se prepara para o futuro da seguinte forma:
a. ( ) Identificando as melhores soluções possíveis para aqueles problemas ou desafios que requerem atenção imediata.
b. ( ) Identificando tendências e oportunidades no mercado que possam resultar na criação de serviços ou produtos inovadores no ramo de negócio da empresa ou possam atender a novos mercados.


c. ( ) Identificando aqueles problemas que, se resolvidos, irão manter e melhorar nossos serviços ou produtos e nossa posição de mercado

d. ( ) Identificando as tendências de negócios cujo potencial a longo prazo já foi demonstrado por outras empresas e podem ajudar a resolver os problemas relativos aos produtos/serviços de nossa empresa.

19. A estrutura de nossa empresa é:

a. ( ) Funcional por natureza (isto é, organizada em departamentos).

b. ( ) Orientada pelo serviço/produto ou pelo mercado.

c. ( ) Essencialmente funcional, porém possui também uma estrutura orientada para serviços ou mercados nas áreas que são mais novas.

d. ( ) Continuamente mudando para permitir um melhor aproveitamento das oportunidades ou resolver problemas assim que eles surgem.

20. Os procedimentos que a Organização usa para avaliar seu desempenho são mais bem descritos como:

a. ( ) Descentralizados e participativos, encorajando todos os membros da organização a se envolverem.

b. ( ) Orientados para solicitações de relatórios que exigem atenção imediata.

c. ( ) Centralizados e basicamente de responsabilidade da alta gerência.

d. ( ) Centralizados em áreas de serviços/produtos mais estáveis, e mais participativos em áreas mais novas ou emergentes. 